\title{
Research International journal of Cancer Therapy and Radiology
}

\section{Research Article}

\section{The Association between Diet} and Esophageal Cancer in

\section{Afghanistan: A Case-Control Study}

\author{
Hafiza Jamily ${ }^{1}$, Beheshta Baraki ${ }^{2}$, Marhaba Barekzai ${ }^{3}$, Ahmad Mujtaba \\ Barekzai4*
}

${ }^{1}$ National Cancer Control Program, Ministry of Public Health, Kabul, Afghanistan.

${ }^{2}$ Department of medicine in Privet Hospital, Kabul, Afghanistan.

${ }^{3}$ Public health faculty of Kabul Medical University, Afghanistan.

${ }^{4}$ Department of Public Nutrition, Ghazanfar Institute of Health Science, Kabul, Afghanistan
Received: 22 January, 2021

Accepted: 09 February, 2021

Published: 10 February, 2021

*Corresponding author: Ahmad Mujtaba Barekzai, Department of Public Nutrition, Ghazanfar Institute of Health Science (GIHS); Tel:0093784913193,

E mail: Mujtaba Barekzai.7@gmail.com

Keywords: Diet, Esophageal cancer, case-control study.

Copyright: (C) 2021 Mujtaba Barekzai A, et al. This is an open access article distributed under the Creative Commons Attribution License, which permits unrestricted use, distribution, and reproduction in any medium, provided the original work is properly cited.

\begin{abstract}
Introduction: Esophageal cancer is one of the most common cancers worldwide. According to World Health Organization (WHO) estimates, esophageal cancer is the fourth most common cancer among Afghan men and the fifth most common cancer among Afghan women in 2018. Data on the link between diet and disease are extremely limited in Afghanistan. Therefore, we aimed to investigate the relationship between diet and esophageal cancer in Afghanistan. In this hospital-based case-control study, 84 esophageal cancer patients (newly diagnosed), and 164 controls with no history of chemotherapy or radiotherapy (due to cancer) were included. The cases and controls are aged between 20 and 75 years and matched in terms of age \pm 5 year and sex. All participants were interviewed face to face by trained female investigators using structured questionnaires. Differences in general characteristics and diet between cases and controls were examined by the t-test and chi-square test. The Binary Logistic Regression was used to examine the association between food consumption and esophagus cancer. The mean age of study participants was 55 years. The salty food 1 time or more per day 9.3 times (95\% CI: 3.390-25.807), intake of meat 1 time or more per day 7.345 times ( $95 \%$ CI: 079-26.083), and pepper 1 time or more per day 2.342 times (95\% CI: 0.968- 1.456) were increased the odds of esophageal cancer in Afghans population.
\end{abstract}

Conclusion: We found that high intake of salty food, pepper, and red meat positively associated with risk of esophageal cancer and the higher intake of fruits, vegetables, fish, and poultry reduce the risk of esophageal cancer in Afghans population. Further studies (e.g. cohort studies) with a large sample size are required to establish this association.

\section{Introduction}

Esophageal cancer is one of the most common cancers worldwide [1]. Esophageal cancer in men are 3 to 4 times more likely than the women in developed countries [2]. Esophageal cancer is the eighth most common cancer and the sixth leading cause of death from cancer in the world [3, 4]. According to World Health Organization (WHO) estimates, there are around 19,450 new cancer cases from 38 million populations in Afghanistan. Esophageal cancer is the fourth most common cancer among Afghan men and the fifth most common cancer among Afghan women in 2018 [5, 6]. A study in Afghanistan showed that the high incidence risk of esophageal cancer in the Uzbek and Turkmen ethnic group [7]. Several studies have been conducted on the economic burden of esophageal cancer. For instance, a study in Canada reported that the costs estimate $\$ 50620$ (95\%CI: \$47677 - \$53562) for esophageal cancer beyond 1 year after diagnosis [8].

Risk factor of esophageal cancer include genetic [9], sex [10], tobacco [11], alcohol [12], obesity [13], Human papillomavirus (HPV) [14], chemical exposure [15], race/ethnicity, and Dietary intake have long been associated with the risk of esophageal cancer [16, 17]. For instance, a case-control study in Uruguay, which includes 261 cases and 522 controls showed that eating daily barbecue meat increases the risk of esophageal cancer [18]. Another case-control study showed that high intake of hot foods, fried and barbecued meats increased the risk of esophageal cancer [19]. Most of case-control studies showed that consumed fewer fresh fruits, and raw vegetables increased the risk of esophageal cancer $[20,21]$.

Moreover, a case-control study in South America showed that consumed hot beverage increases the risk of esophageal cancer and the high intake of fruits, and vegetables decreased the risk of esophageal cancer [22]. Several studies showed that drinking the high temperature of tea, and coffee increases the risk of esophageal cancer [23, 24]. Further, several studies found that salted meat increases the risk of esophageal cancer $[25,26]$. According to a study in Uruguay showed that consumed red meat, stewed meat, and salted meat related with moderate to strong effects on the risk esophageal cancer [27]. On the other hand, most of case-control studies showed that high intake of white meat, poultry, and fish presented moderate inverse associations with esophageal cancer $[28,29]$. Some studies showed that high intake of lean meat, fruits, and 
Citation: Mujtaba Barekzai A, Hafiza J, Beheshta B, Marhaba B (2021) The association between diet and esophageal cancer in Afghanistan: a case-control study. Rea Int J of Cancer therapy and Rad: 001-006. DOI: 10.37179/rijctr.000001

raw vegetables decreased the risk of esophageal cancer [29-33]. Given these findings, it seems that the intake of fruits, vegetables, and lean meat decreased the risk of esophageal cancer. No previous study has examined the association between diet and esophageal cancer in Afghanistan. In the current study, we aimed to examine the association between diet and risk of esophageal cancer among Afghan adults.

\section{Materials and Methods}

Study Design: This is a hospital-based case-control study.

Study Participants: The case-control study was conducted (maximum one month elapsed since the detection) in the Jamhuriat hospital, Kabul-Afghanistan in the period of Jan-Nov 2018. Cases were 82 patients with esophageal cancer and 164 controls. We considered the odds ratio of 2.5 . We assumed a type I error of $5 \%$, study power of $80 \%$ $(\beta=0.20)$, and the ratio of cases to controls as 1 . Cases were selected from the patients who have been histologically diagnosed with esophageal hospital. Controls were selected from the patients who are admitted to other wards of Jamhuriat hospital. The cases and controls are aged between 20 and 75 years and matched in terms of age \pm 5year and sex. All cases and controls provide written informed consent. The inclusion and exclusion criteria were the following: the inclusion criterias are to have a histological diagnosis of esophageal squamous cell carcinoma in case criteria and to be insufficiently good physical and mental health to Those with a history of chemotherapy or radiotherapy (due to cancer) were not included in the study.

Assessment of variables: A pretested questionnaire was used which the questionnaire included information on socio-demographical factors, about age, sex, physical activity, residence (urban and rural), smoking (less than 3 cigarettes a day, 3-5 cigarettes a day, 6-9 cigarettes a day, $\geq 10$ cigarettes a day), family history of cancer, drink tea, fried foods, outdoor foods, salt intake, meal temperature, spicy food consumption, and drink tea. A short form of the International Physical Activity Questionnaire (IPAQ) was used for measuring the physical activity of participants. Weight and height were measured to the nearest $0.1 \mathrm{~kg}$ using a digital scale and tape measure with minimal clothes without shoes and standing position. Body mass index (BMI) was calculated as weight (kg) divided by height squared $(\mathrm{m} 2)$.

Data Collection: Open-end questions were used in the current study. During a year, the common dietary intakes of participants before the diagnosis of gastric cancer in cases, and before the interview in controls were examined. All participants were interviewed face to face by trained female investigators using structured questionnaires. The frequency of consumption was divided into four categories, which is never, 1time or more per month, 1 time or more per week, and 1 time or more per day. Each interview usually took about 40 or 50 minutes.

Sampling: Controls meeting our inclusion criteria were selected from the hospital population. We calculated required sample size [34]. Eligible subjects including 82 cases and 164 controls were recruited. Written informed consent was obtained from all subjects.

Statistical Analysis: Differences in general characteristics and diet between cases and controls were examined by the t-test and chi-square test. The Binary Logistic Regression was used to examine the association between food consumption and esophagus cancer. A p-value of $<0.05$ was considered significant. All statistical analyses will be done using the Statistical Package for Social Science version 24 (SPSS Inc., Chicago, Illinois, USA). cancer and have been registered in the cancer ward of the Jamhuriat give reliable answers to the questionnaire in the case and control criteria.

\section{Results}

General characteristics of study participants, separately by cases and controls in (Table 1). Compared with controls, cases had a lower mean weight, and BMI. They were more likely to be physically active, live in rural areas, family history of cancer, smoke 6-9 cigarettes a day, and $\geq 10$ cigarettes a day than controls. Dietary habits of study participants, separately by cases and controls in (Table 2). Compared with controls, cases were more likely to drink hot tea, fried foods, outdoor foods, have a high salt intake, and have a high temperature of the meal. They were less likely to spicy food consumption, drink moderate, cold tea, have the low and median salt intake, and have the low and moderate temperature of the meal than controls. Association between food consumption and esophageal cancer, separately by cases and controls in (Table 3). Compared with controls, cases had higher intakes of salty

\begin{tabular}{|c|c|c|c|}
\hline \multicolumn{1}{|l|}{ Table1: General Characteristics of study participants. } \\
\hline & $\begin{array}{c}\text { Cases } \\
(\mathbf{n = 8 2})\end{array}$ & $\begin{array}{c}\text { Controls } \\
(\mathbf{n = 1 6 4})\end{array}$ & $\mathbf{P}^{* *}$ \\
\hline Age (years) & $56 \pm 12$ & $54 \pm 11$ & 0.56 \\
\hline Weight $(\mathrm{kg})$ & $67 \pm 15$ & $77 \pm 12$ & $<0.001$ \\
\hline BMI $\left(\mathrm{kg} / \mathrm{m}^{2}\right)$ & $24 \pm 3$ & $28 \pm 3.72$ & $<0.001$ \\
\hline Physical activity (MET-h/week) & $3 \pm 1$ & $2 \pm 0.99$ & $<0.001$ \\
\hline Male (\%) & 66 & 59 & 0.873 \\
\hline Residence (rural, \%) & 77 & 35 & $<0.001$ \\
\hline Smoking & & & 0.91 \\
\hline Less than 3 cigarettes a day & 2 & 7 & \\
\hline 3-5 cigarettes a day & 40 & 47 & \\
\hline 6-9 cigarettes a day & 51 & 49 & \\
\hline$\geq 10$ cigarettes a day & 17 & 6 & \\
\hline Family history of cancer & 39 & 7 & $<0.001$ \\
\hline
\end{tabular}

Abbreviations: MET (Metabolic Equivalents) and BMI (Body Mass Index) *All values are mean \pm SD unless indicated.

** $\mathrm{P}$ values were obtained from independent Student's $\mathrm{t}$ test or chisquare test, where appropriate.

\begin{tabular}{|c|c|c|c|}
\hline Table 2: Dietary habits of study participants. & & \\
\hline & $\begin{array}{c}\text { Cases } \\
(\mathbf{n = 8 2})\end{array}$ & $\begin{array}{c}\text { Controls } \\
(\mathbf{n = 1 6 4})\end{array}$ & $\mathbf{P}^{* *}$ \\
\hline Drink tea & 78 & 59 & $<0.001$ \\
\hline Hot & 10 & 27 & \\
\hline Moderate & 3 & 5 & \\
\hline Cold & 48 & 2.4 & $<0.001$ \\
\hline Fried food consumption (\%) & 58.5 & 30 & $<0.001$ \\
\hline Outdoor food usage (\%) & 16 & 27 & 0.056 \\
\hline Spicy food consumption (\%) & & & 0.001 \\
\hline Salt intake (\%) & 13 & 47 & \\
\hline Low & 34 & 62 & \\
\hline Median & 43 & 5 & \\
\hline High & & & $<0.001$ \\
\hline Hot & 32 & 2 & \\
\hline Moderate & 15 & 43 & \\
\hline Cold & 52 & 73 & \\
\hline
\end{tabular}


Citation: Mujtaba Barekzai A, Hafiza J, Beheshta B, Marhaba B (2021) The association between diet and esophageal cancer in Afghanistan: a case-control study. Rea Int J of Cancer therapy and Rad: 001-006. D0I: 10.37179/rijctr.000001

Table 3: Association between food consumption and esophageal cancer.

\begin{tabular}{|c|c|c|c|c|}
\hline & $\begin{array}{c}\text { Cases } \\
(\mathrm{n}=82)\end{array}$ & $\begin{array}{l}\text { Controls } \\
(n=164)\end{array}$ & OR & (CI 95\%) \\
\hline \multicolumn{5}{|l|}{ Fish and poultry } \\
\hline Never & 7 & 1 & 1 & \\
\hline 1 time or more per month & 12 & 15 & 0.190 & $0.020-1.837$ \\
\hline 1 time or more per week & 25 & 46 & 0.78 & $0.009-0.667$ \\
\hline 1 time or more per day & 2 & 4 & 0.204 & $0.024-1.752$ \\
\hline \multicolumn{5}{|l|}{ Fruits } \\
\hline Never & 40 & 6 & 1 & \\
\hline 1 time or more per month & 14 & 17 & 0.124 & $0.0041-0.376$ \\
\hline 1 time or more per week & 15 & 34 & 0.066 & $0.023-0.189$ \\
\hline 1 time or more per day & 15 & 27 & 0.083 & $0.29-0.242$ \\
\hline \multicolumn{5}{|l|}{ Vegetables } \\
\hline Never & 10 & 3 & 1 & \\
\hline 1 time or more per month & 11 & 29 & 0.791 & $0.183-1.423$ \\
\hline 1 time or more per week & 28 & 36 & 0.233 & $0.059-0.929$ \\
\hline 1 time or more per day & 17 & 34 & 0.150 & $0.036-0.618$ \\
\hline \multicolumn{5}{|l|}{ Salty food } \\
\hline Never & 2 & 56 & 1 & \\
\hline 1 time or more per month & 5 & 11 & 0.798 & $0.052-1.444$ \\
\hline 1 time or more per week & 56 & 3 & 0.23 & $0.128-0.776$ \\
\hline 1 time or more per day & 47 & 13 & 9.3 & $3.390-25.807$ \\
\hline \multicolumn{5}{|l|}{ Meat } \\
\hline Never & 5 & 3 & 1 & \\
\hline 1 time or more per month & 25 & 28 & 0.079 & $0.22-0.434$ \\
\hline 1 time or more per week & 49 & 52 & 0.835 & $0.66-1.432$ \\
\hline 1 time or more per day & 5 & 1 & 7.345 & $2.079-26.083$ \\
\hline \multicolumn{5}{|l|}{ Pepper } \\
\hline Never & 3 & 48 & 1 & \\
\hline 1 time or more per month & 14 & 3 & 0.097 & $0.024-0.360$ \\
\hline 1 time or more per week & 19 & 11 & 0.327 & $0.146-0.729$ \\
\hline 1 time or more per day & 29 & 2 & 2.342 & $0.968-1.456$ \\
\hline
\end{tabular}

food, meat, and pepper. They consumed lower number of fish-poultry, fruits, and vegetable than control. The salty food (OR=9.3, 95\%CI: 3.39025.807), meat (OR=7.345, 95\% CI: 079-26.083), and pepper (OR=2.342, 95\% CI:.0.968- 1.456) were increased the odds of esophageal cancer.

\section{Discussion}

In the current study, a significant positive association was seen between diet and odds of esophageal cancer in Afghanistan. The association was independent of potential confounders such as age, sex, and other various environmental factors. To the best of our knowledge, this is the first study examining the relationship between diet and risk of esophageal cancer in Afghanistan. Esophageal cancer is the eighth most common cancer and the sixth leading cause of death from cancer in the world [35, 36]. Diet is very important variable for increase and decrease the risk of esophageal cancer(31). For instance, a case-control study in Taiwan showed that consumed salted food (OR=2.3, 95\%CI: 1.2-4.2), and pickled vegetables (OR=2.5,95\%CI: $1.3-4.5)$ less than one week increased the risk of esophageal cancer in men [37].
A case-control study in Uruguay revealed that high intake of alcohol, tobacco, and salted meat increased the risk of esophageal cancer [27]. Some other studies showed that lower intake of fruit, and vegetable increase the risk of esophageal cancer [38]. A retrospective cohort study in China showed that a positive family history, low education, surface water use, and pork consumption in the male gender were increased the risk of esophageal cancer, while smoking and alcohol use, pickled vegetable and moldy food consumption were not risk factors in this study [39]. Additionally, a study in North eastern region of India showed that consumption of very spicy food, hot foods, and beverages was positively associated with the risk of esophageal cancer. However, green leafy vegetables, and fruits were decreased the risk of esophageal cancer [40]. A case-control study in south western china revealed that the smoking (OR=4.06, 95\%CI: 1.55-10.6), eating food rapidly (OR=5.84, 95\%CI, 2.05-16.7), drinking shallow ground water (OR=4.18, 95\%CI, 1.30-13.4), frequent intake of pickled vegetables (OR=2.12, 95\%CI, 1.00-4.49), and alcohol drinking (OR=2.49,95\% CI: $1.06-5.85)$ were increased the risk of esophageal cancer(41). Although, frequent intake of fresh fruit $(\mathrm{OR}=0.42$, $95 \% \mathrm{CI}, 0.19-0.89)$, fresh vegetables (OR= $0.62,95 \% \mathrm{CI}, 0.32-1.17)$, and eggs (OR=0.59, 95\%CI, 0.25-1.39) decreased the risk of esophageal cancer [41].

Several studies showed that high intake of the hot drinking beverage such as coffee with milk but not coffee alone, and tea increased the risk of esophageal cancer [42, 43]. Several studies showed that high intake of the hot food, and fast eating speeds increased the risk of esophageal cancer [44-46]. On the other hand, a case-control study revealed that dietary intake of protein, vitamin C, B1, and E reduced the risk of esophageal cancer [47]. An epidemiology study showed that higher intake of fruits, and vegetable was reduced the risk of esophageal cancer [47]. Several studies showed that the high consumption of carrots, green vegetables, and fresh fruits were reduced the risk of esophageal cancer [32, 48]. In conclusion, most studies showed the positive association of the diet and esophageal cancer among the adult population.

Our study had several strengths. This is the first study to examine the association between diet and esophageal cancer in Afghanistan. Easily accessible patients in the hospital, and enough time for filling the questioner. However, there are also a few limitations, due to the casecontrol design of the study, recall bias might be present. In fact, prior epidemiological studies have demonstrated that cases usually recall their dietary intakes better than controls. The use of hospital controls may be criticized because their dietary habits may differ from those of the general population. and the language barrier.

In conclusion, we found that high intake of salty food, pepper, and meat positively associated with risk of esophageal cancer, and the high intake of fruits, vegetables, fish, and poultry reduce the risk of esophageal cancer in the Afghans study group. Further studies (e.g. cohort studies) with a large sample size are required to establish this association.

Statement of Authorship: HJ contributed to conception, design, search, statistical analyses. BB and MB contributed to data interpretation and manuscript drafting, data clearing, statistical analyses and drafting the manuscript. AMB supervised the study. All authors approved the final manuscript for submission.

Conflicts of interest: All authors declared no potential personal or financial conflicts of interest.

\section{References}

1. Eslick GD (2009) Epidemiology of esophageal cancer. Gastroenterology Clinics of North America 38: 17-25. Link: http://bit.ly/2MR4qeW

2. Pakzad R, Mohammadian-Hafshejani A, Khosravi B, Soltani S, Pakzad I, et al. (2016) The incidence and mortality of esophageal cancer and their 
Citation: Mujtaba Barekzai A, Hafiza J, Beheshta B, Marhaba B (2021) The association between diet and esophageal cancer in Afghanistan: a case-control study. Rea Int J of Cancer therapy and Rad: 001-006. D0I: 10.37179/rijctr.000001

relationship to development in Asia. Annals of translational medicine 4: 29 Link: http://bit.ly/3qgPOzr

3. Di Pardo BJ, Bronson NW, Diggs BS, Thomas CR, Hunter JG, et al. (2016) The global burden of esophageal cancer: a disability-adjusted life-year approach. World journal of surgery 40: 395-401. Link: http://bit.ly/3jBIRw3

4. Ferlay J, Shin HR, Bray F, Forman D, Mathers C, et al. (2010) Estimates of worldwide burden of cancer in 2008: GLOBOCAN 2008. Int J Cancer 127 2893-2917. Link: http://bit.ly/3rDRBnk

5. https://www.who.int/cancer/country-profiles/AFG_2020.pdf?ua=1. Link: https://bit.ly/3a0Jtae

6. http://gco.iarc.fr/today/data/factsheets/populations/4-afghanistan-fact-sheets pdf. Link: https://bit.ly/2MGbA60

7. Hamrah MS, Hamrah MH, Rabi M, Wu HX, Hao C-N, et al. (2015) Prevalence of esophageal cancer in the northern part of afghanistan. Asian Pacific Journal of Cancer Prevention 15: 10981-10984. Link: http://bit.ly/3cVZyji

8. de Oliveira C, Bremner KE, Pataky R, Gunraj N, Chan K, et al. (2013) Understanding the costs of cancer care before and after diagnosis for the 21 most common cancers in Ontario: a population-based descriptive study. CMAJ open 1: E1-E8. Link: http://bit.ly/3cWK8vk

9. Kuwano H, Kato H, Miyazaki T, Fukuchi M, Masuda N, et al. (2005) Genetic alterations in esophageal cancer. Surgery today 35: 7-18. Link: http://bit. Iy/2N7tTAl

10. Bohanes P, Yang D, Chhibar RS, Labonte MJ, Winder T, et al. (2012) Influence of sex on the survival of patients with esophageal cancer. Journal of clinical oncology 30: 2265. Link: http://bit.ly/2LwPG4i

11. Fan Y, Yuan J-M, Wang R, Gao Y-T, Yu MC (2008) Alcohol, tobacco, and diet in relation to esophageal cancer: the Shanghai Cohort Study. Nutrition and cancer 60: 354-363. Link: http://bit.ly/2Z1DXOg

12. Castellsagué X, Muñoz N, De Stefani E, Victora CG, Castelletto R, et al. (1999) Independent and joint effects of tobacco smoking and alcohol drinking on the risk of esophageal cancer in men and women. International journal of cancer 82: 657-664. Link: http://bit.ly/2NcKcfr

13. Vaughan TL, Davis S, Kristal A, Thomas DB (1995) Obesity, alcohol, and tobacco as risk factors for cancers of the esophagus and gastric cardia: adenocarcinoma versus squamous cell carcinoma. Cancer Epidemiology and Prevention Biomarkers 4: 85-92. Link: http://bit.ly/3tJpQv9

14. Kawaguchi H, Ohno S, Araki K, Miyazaki M, Saeki H, et al. (2000) p53 polymorphism in human papillomavirus-associated esophageal cancer Cancer research 60: 2753-2755.Link: http://bit.ly/3qhakot

15. Kamangar F, Chow W-H, Abnet CC, Dawsey SM (2009) Environmental causes of esophageal cancer. Gastroenterology Clinics of North America 38 27-57. Link: http://bit.ly/3jwFeGF

16. Brown $L$ (2000) The role of race/ethnicity in the epidemiology of esophagea cancer. Journal of the Association for Academic Minority Physicians: the official publication of the Association for Academic Minority Physicians 11: 32. Link: https://bit.ly/3a11B3K

17. Palladino-Davis A, Mendez B, Fisichella P, Davis C (2015) Dietary habits and esophageal cancer. Diseases of the Esophagus. 28: 59-67. Link: http://bit. Iy/3cUN6jX

18. De Stefani E, Muñoz N, Estève J, Vasallo A, Victora CG, et al. (1990) Mate drinking, alcohol, tobacco, diet, and esophageal cancer in Uruguay. Cancer Research 50: 426-431. Link: http://bit.ly/2OlzMeh

19. Jessri M, Rashidkhani B, Hajizadeh B, Jessri M, Gotay C (2011) Macronutrients, vitamins and minerals intake and risk of esophagea squamous cell carcinoma: a case-control study in Iran. Nutrition journal 10 137. Link: http://bit.ly/2LybCMu

20. Cook-Mozaffari P, Azordegan F, Day N, Ressicaud A, Sabai C (1979) Oesophageal cancer studies in the Caspian Littoral of Iran: results of a casecontrol study. British journal of cancer 39: 293-309. Link: http://bit.ly/3a0ZXz8
21. Launoy G, Milan C, Day NE, Pienkowski MP, Gignoux M, et al. (1998) Diet and squamous-cell cancer of the oesophagus: A French multicentre case-control study. International Journal of Cancer 76: 7-12. Link: http://bit.ly/3tEiJUR

22. Castellsagué X, Muñoz N, De Stefani E, Victora CG, Castelletto R (2000) Influence of mate drinking, hot beverages and diet on esophageal cancer risk in South America. International Journal of Cancer 88: 658-664. Link: http://bit. ly/3p1SSmo

23. Islami F, Boffetta P, Ren JS, Pedoeim L, Khatib D, et al. (2009) Hightemperature beverages and foods and esophageal cancer risk-A systematic review. International journal of cancer 125: 491-524. Link: http://bit.ly/3rySWeY

24. Islami F, Pourshams A, Nasrollahzadeh D, Kamangar F, Fahimi S, et al. (2009) Tea drinking habits and oesophageal cancer in a high risk area in northern Iran: population based case-control study. Bmj 338: b929. Link: http://bit.ly/3oYhHQO

25. Zhao L, Li Y-C, Wu J-P, Zhao Y-J, Wang R-B, et al. (2019) Increased risk of esophageal squamous cell carcinoma associated with frequent and long-term consumption of salted meat and salted fat. Journal of International Medical Research 47: 3841-3849. Link: http://bit.ly/3tFYu9c

26. Sihao Lin, Xiaorong W, Chengyu H, Xudong L, Jin Zhao, et al. (2015) Consumption of salted meat and its interactions with alcohol drinking and tobacco smoking on esophageal squamous-cell carcinoma." International Journal of Cancer 137: 582-589. Link: http://bit.ly/3cPVO30

27. De Stefani E, H Deneo-P, A L Ronco, P Boffetta, P Brennan, et al. (2003) Food groups and risk of squamous cell carcinoma of the oesophagus: a case-control study in Uruguay." British journal of cancer 89: 1209-1214. Link: https://go.nature.com/3p1Wzsg

28. Vikash S, Eduardo De S, Paul B, Paolo B (2003) Mate consumption and the risk of squamous cell esophageal cancer in Uruguay." Cancer Epidemiology and Prevention Biomarkers 12: 508-513. Link: http://bit.ly/2Z1Uj9C

29. Jessri M, Bahram R, Bahareh H, Maryam J, Carolyn G (2011) Macronutrients, vitamins and minerals intake and risk of esophageal squamous cell carcinoma: a case-control study in Iran." Nutrition journal 10: 137. Link: http:// bit.ly/2LybCMu

30. Cheng KK, NE Day (1996) Nutrition and esophageal cancer." Cancer Causes \& Control 7: 33-40. Link: http://bit.ly/3tK68jc

31. Tuyns AJ, E Riboli, G Doornbos, G Péquignot (1987) Diet and esophagea cancer in Calvados (France) 9: 81-92. Link: http://bit.ly/3cVrUKP

32. Freedman ND, Yikyung Park, Amy F. Subar, Albert R. Hollenbeck, Michae FL, et al. (2007) Fruit and vegetable intake and esophageal cancer in a large prospective cohort study." International journal of cancer 12: 2753-2760. Link: https://bit.ly/3tlplfC

33. Jeurnink SM, F L Büchner, H B Bueno-de-Mesquita, $P$ D Siersema, $H$ Boshuizen, et al. (2012) Variety in vegetable and fruit consumption and the risk of gastric and esophageal cancer in the European prospective investigation into cancer and nutrition." International journal of cancer 131: E963-E973. Link: http://bit.ly/2YYwn7|

34. Di Pardo BJ BN, Diggs BS, Thomas CR, Hunter JG, Dolan JP, et al. (2016) The global burden of esophageal cancer: a disability-adjusted life-year approach. World journal of surgery 40: 395-401. Link: http://bit.ly/3jBIRw3

35. Ferlay JSH, Bray F, Forman D, Mathers C, Parkin DM, et al. (2010) Estimates of worldwide burden of cancer in 2008: GLOBOCAN 2008. International journal of cancer 127: 2893-2917. Link: http://bit.ly/3rDRBnk

36. Hsin-Chia Hung, Meng-Chuan Huang, Jang-Ming Lee, Deng-Chyang Wu Hon-Ki Hsu, et al. (2004) Association between diet and esophageal cance in Taiwan." Journal of gastroenterology and hepatology 19: 632-637. Link: https://bit.ly/2N7JNv4

37. Curtis Mettlin, Saxon Graham, Roger Priore, James Marshall, Mya Swanson (1981) Diet and cancer of the esophagus. 143-147. Link: https://bit.ly/3oZO4h7

38. Yu Y, P R Taylor, J Y Li, S M Dawsey, G Q Wang, et al. (1993) Retrospective cohort study of risk-factors for esophageal cancer in Linxian, People's 
Citation: Mujtaba Barekzai A, Hafiza J, Beheshta B, Marhaba B (2021) The association between diet and esophageal cancer in Afghanistan: a case-control study. Rea Int J of Cancer therapy and Rad: 001-006. DOI: 10.37179/rijctr.000001

Republic of China." Cancer Causes \& Control 4: 195-202. Link: http://bit. ly/3aJuZe6

39. R K Phukan, C K Chetia, M S Ali, J Mahanta (2001) Role of dietary habits in the development of esophageal cancer in Assam, the north-eastern region of India." Nutrition and cancer 39: 204-209. Link: http://bit.ly/3a3uEE7

40. Yang CX, Hua-yu Wang, Zhi-ming Wang, Hui-zhang Du, De-ming Tao, et al. (2005) Risk factors for esophageal cancer: a case-control study in Southwestern China." Asian Pac J Cancer Prev 6: 48-53. Link: http://bit.ly/2NdhGu9

41. Farhad Islami, Paolo Boffetta, JianSong Ren, Leah Pedoeim, Dara Khatib, et al. (2009) High-temperature beverages and foods and esophageal cancer risk-A systematic review." International journal of cancer 125: 491-524. Link: http://bit.ly/3rySWeY

42. X Castellsagué, N Muñoz, E De Stefani, C G Victora, R Castelletto, et al (2000) Influence of mate drinking, hot beverages and diet on esophageal cancer risk in South America." International Journal of Cancer 88: 658-664. Link: http://bit.ly/3p1SSmo
43. Jing Lin, Runming Zeng, Weihua Cao, Rongcheng Luo, Jing Chen, et al. (2011) Hot beverage and food intake and esophageal cancer in southern China." Asian Pac J Cancer Prev 12: 2189-2192. Link: http://bit.ly/2LzmF89

44. Andrici J, Guy D. Eslick (2015) Hot food and beverage consumption and the risk of esophageal cancer: a meta-analysis." American journal of preventive medicine 49: 952-960. Link: http://bit.ly/36WQFCe

45. Deybasso HA, Kedir Teji Roba, Berhanu Nega, Tefera Belachew (2020) Dietary Determinants of Esophageal Cancer in Arsi Zone, Central Ethiopia: A Case-Control Study. Link: https://bit.ly/3rwJd8M

46. A Decarli, P Liati, E Negri, S Franceschi, C La Vecchia (1987) Vitamin A and other dietary factors in the etiology of esophageal cancer 10: 29-37. Link: http://bit.ly/3jXXI9D

47. Steinmetz KA, John D. Potter (1996) Vegetables, fruit, and cancer prevention a review." Journal of the american dietetic association 96: 1027-1039. Link: http://bit.ly/3cWA8SI

\section{QUESTIONNAIRE:}

Date:

1. Medical Record Number (

Hospital:

2. Ward ( )

3. Gender
Male
Female

4. Age...................

5. Weight

6. BMI

7. Where do you live?

$\bigcirc$ Urban $\bigcirc$ Rural

8. Have you smoked?

Never

Ex-smokers

Current smokers

9. Smoking

Less than 3 cigarettes a day

3-5 cigarettes a day

6-9 cigarettes a day

$>\geq 10$ cigarettes a day

10. Family history of cancer? Yes or No

If yes, type of cancer

11. Drink tea?
Hot
Moderate
Cold

12. Fried Food Consumption? Yes/No

13. Outdoor food usage? Yes/No

14. Spicy food consumption? Yes/No

15. Salt intake?
Low
Median
High

16. Meal temperature?

Hot

\section{Moderate \\ Cold}

17. How often did you eat fish and poultry?

Never

1 time or more per month

1 time or more per week

1 time or more per day

18. How often did you eat fruits?

Never

1 time or more per month

1 time or more per week

1 time or more per day

19. How often did you eat salty food?
Never
1 time or more per month
1 time or more per week
1 time or more per day

20. How often did you eat vegetables?

$\bigcirc$ Never

1 time or more per month

1 time or more per week

1 time or more per day

21. How often did you eat meat?
Never
1 time or more per month
1 time or more per week
1 time or more per day

22. How often did you eat peppers?
Never
1 time or more per month
1 time or more per week
1 time or more per day

\section{Physical Activity Questionnaire:}

1. During the last 7 days, on how many days did you do vigorous physical activities like heavy lifting, digging, aerobics, or fast bicycling?

$$
\text { ........................days per week }
$$

No vigorous physical activities ..........Skip to question 3

2. How much time did you usually spend doing vigorous physical activities on one of those days?

...................Hours per day

..................minutes per day 
Citation: Mujtaba Barekzai A, Hafiza J, Beheshta B, Marhaba B (2021) The association between diet and esophageal cancer in Afghanistan: a case-control study. Rea Int J of Cancer therapy and Rad: 001-006. DOI: 10.37179/rijctr.000001

Donot know/not sure.

3. During the last 7 days, on how many days did you do moderate physical activities like carrying light loads, bicycling at a regular pace, or doubles tennis?

Do not include walking. ....days per week

No moderate physical activites .........Skip to question $\mathbf{5}$

4. How much time did you usually spend doing moderate physical activities on one of those days?

...............hours per day

................minutes per day

Donot know/not sure.

5. During the last 7 days, on how many days did you walk for at least 10 minutes at a time?

............days per week

No walking

Skip to question 7

6. How much time did you usually spend walking on one of those days?

................hours per day

................minutes per day

Donot know/not sure.

7. During the last 7 days, how much time did you spend sitting on a week day?

$$
\begin{aligned}
& \text {..........................minutes per day per day } \\
& \text { Donot know/not sure. }
\end{aligned}
$$

